\title{
The role of indigenous knowledge and local knowledge in water sector adaptation to climate change in Africa: A structured assessment
}

Luckson Zvobgo ( $\sim$ zvobgoluckson@gmail.com )

University of Cape Town https://orcid.org/0000-0003-3400-8003

Peter Johnston

University of Cape Town

Portia Adade Williams

CSIR-Science and Technology Policy Research Institute https://orcid.org/0000-0002-5919-3930

Chrstopher H Trison

University of Cape Town https://orcid.org/0000-0002-5854-1489

Nicholas P Simpson

University of Cape Town https://orcid.org/0000-0002-9041-982X

\section{Systematic Review}

Keywords: IPCC, Africa, climate risk, water adaptation responses, indigenous knowledge and local knowledge

Posted Date: August 2nd, 2021

DOl: https://doi.org/10.21203/rs.3.rs-774241/v1

License: (c) (1) This work is licensed under a Creative Commons Attribution 4.0 International License. Read Full License 


\section{Abstract}

Evidence of human adaptation actions responding to climate impacts is increasing in Africa. However, a holistic understanding of effective adaptation across the diversity of African contexts is still limited at a continental scale. Despite high reliance on indigenous knowledge (IK) and local knowledge (LK) for climate adaptation in Africa, the potential risk reduction of IK and LK and its role in supporting transformative adaptation responses is yet to be established. Here, we assess the influence of IK and LK on the implementation of water sector adaptation in Africa and describe the relationship between adaptation and indigenous and local knowledge systems. Eighteen (18) water sector response types were identified from the academic literature through the Global Adaptation Mapping Initiative (GAMI). The most implemented measures across Africa influenced by IK and LK were household-level and individual measures and included irrigation, rainwater harvesting, water conservation and ecosystem-based measures (mainly agroforestry). Southern, west, and east Africa show relatively high evidence of the influence of IK and LK on the implementation of water adaptation responses while north, and central Africa show lower evidence. At country level, Zimbabwe display highest evidence (77.8\%) followed by Ghana (53.6\%), Kenya (46.2\%) and South Africa (31.3\%). Adaptation responses with IK and LK influence recorded higher evidence of risk reduction compared to articles without IK and LK. Analysis of intended nationally determined contributions (iNDCs) shows the most implemented water adaptation actions in academic literature are consistent with water sector adaptation targets set by most African governments. Yet only $10.4 \%$ of the African governments included IK and LK in adaptation planning in the iNDCs. The study recommends a coordinated approach to adaptation that integrates multiple knowledge sources including IK and LK to ensure greater effectiveness and scalability of current and potential water adaptation measures in Africa.

\section{Introduction}

Climate hazards are projected to intensify in the 21 st century with severe risks projected for both humans and ecosystems (IPCC, 2019b; Global Risk Report, 2021). African countries have contributed relatively little to the greenhouse gas emissions causing climate change, but face many of the most severe risks in key sectors, including: water, food systems, economies, health, and biodiversity (Niang et al., 2014). Anthropogenic climate change has already increased the likelihood of climate shocks in Africa, such as the 2015-2017 Cape Town drought (Otto et al., 2018). Climate change adaptation is thus essential in order to manage current impacts and reduce future risks.

Understanding which adaptation actions are being implemented, how, and the effectiveness of specific responses for reducing risk is crucial for adaptation planning (Owen, 2020; Berrang-Ford et al., 2021 b; Williams et al., 2021). The Intergovernmental Panel on Climate Change (IPCC) defines climate adaptation in human systems as the process of adjustment to actual or expected climate and its effects, to moderate harm or exploit beneficial opportunities (IPCC, 2018). Since the publication of the IPCC 5th Assessment Report (AR5) in 2014, there has been a substantial increase in peer-reviewed publications documenting evidence of climate adaptation responses, with the greatest increase evident in the literature 
on Africa (Berrang-Ford et al., 2021b; United Nations Environment Programme, 2021). Although most of these adaptation processes are still at the early implementation stage (Berrang-Ford et al., 2021b; United Nations Environment Programme, 2021), this growing literature record has improved information on where and how adaptation is taking place, including possible maladaptation threats.

However, little is known in Africa about what effect Indigenous Knowledge (IK) and Local Knowledge (LK) are having on climate change adaptation actions. Indigenous knowledge refers to the understanding, skills, and philosophies developed by societies with long histories of interaction with their natural surroundings (IPCC, 2019b). Local knowledge refers to the understanding and skills developed by individuals and populations, specific to the place where they live (IPCC, 2019b). IK and LK systems in Africa are central to managing resources during periods of resource scarcity and thus to broader and more effective implementation of climate change adaptation options. The highly context-specific nature of adaptation has led scholars to highlight the need for inclusion of local knowledge systems for enhanced efficacy of adaptation projects (Nyong et al., 2007; Makondo and Thomas, 2018). A range of localised case studies have highlighted the importance of indigenous knowledge and local knowledge for coping responses and adaptation scalability (Nkomwa et al., 2014; Kanda et al., 2017; Mwaniki and Stevenson, 2017; Opare, 2018; Williams et al., 2020). Recent IPCC Special Reports for AR6 highlight the potential role IK and LK can play to reduce climate risks to natural and managed ecosystems (IPCC, 2019b; IPCC, 2019a; IPCC, 2019c). This role of indigenous and local people has been recognised by the Green Climate Fund, Global Environment Facility, and International Climate Initiative as key to facilitating adaptation with important stakeholders and framing adaptation and financing of projects in Africa (United Nations Environment Programme, 2021). A synthesis of the inclusion of IK and LK in climate change adaptation across Africa is crucial to policymakers for several reasons, including: (1) assessing which adaptation actions include IK and LK and where these are being implemented, (2) assessing the effectiveness of adaptation options that include IK and LK for reducing risk, (3) assessing the adaptation gap in Africa, (4) and prioritising the distribution of limited financial resources to adaptation options and guiding decisions on adaptation funding from multilateral funders.

Here, we begin to fill these knowledge gaps by reviewing evidence of the use of IK and LK in the implementation of water adaptation responses across Africa. Water is a key resource linking multiple different sectors (e.g., food, energy, health) in climate adaptation (United Nations Economic Commission for Europe, 2009; UN Water, 2013; Global Water Partnership, 2018). We unpack how IK and LK possessed by communities is used in the implementation of water adaptation responses in Africa. As climate change continues to affect water resources and availability in Africa, several adaptation measures are being implemented across water users and communities. Mapping where this adaptation is taking place is vital for planning and feasibility assessment of some of the water adaptation measures including the different types of knowledge being used for decision making during adaptation. Here we provide the first regional assessment on the role of IK and LK in adaptation responses related to water in Africa.

\section{Methods}


We conducted a structured assessment (Kofod-Petersen, 2012) of the academic literature published between 2013 and 2019, aligned with the timeframe of the IPCC 6th Assessment. The data used was obtained from the Global Adaptation Mapping Initiative (GAMI), a global dataset with 1682 coded articles on human adaptation to climate change. GAMI articles were retrieved from Web of Sciences, Medline, and Scopus. Details on how the articles were retrieved, the screening process (machine learning plus human screening), and coding are provided in Berrang-Ford et al. (2021b) with accompanying protocols by Berrang-Ford et al. (2021a), Fischer et al. (2021) and Lesnikowski et al. (2021). The inclusion and exclusion criteria for the articles used in the GAMI is explained in Fischer et al. (2021), particularly, documents that reported on responses that constituted adaptation based on a strict definition of the term: behaviours that directly aimed to reduce risk or vulnerability. Articles that were theoretical, or assessments of potential or future adaptation, were excluded to maintain the empirical foundation of observed responses to climate change. Our assessment focused on the evidence of human adaptation responses to climate change in the water sector across Africa. Five hundred and seventy (570) articles were assessed for evidence of water adaptation responses implemented across sectors. We segregated articles identified to have evidence of water adaption responses to climate change in Africa. We then assessed the evidence and role of IK and LK on the implementation of the adaptation responses (see Fig. 1).

\subsection{Framing water adaptation responses and IK and LK.}

To extract relevant water adaptation responses in the GAMI, we first define water adaptation responses. We defined water adaptation responses from two perspective. We first define water adaptation responses as responses or actions that were undertaken to reduce the risk that is water related, for example, the risk that emanates from hazard and exposure caused by floods, droughts, groundwater depletion, soil moisture reduction e.g., increase groundwater abstraction, mulching. Then we defined water adaptation responses in terms of actual adaptation interventions that were water related in their implementation, for example, practices such as irrigation, soil moisture conservation, rainwater harvesting, and wastewater reuse. The framing of the water adaptation responses was based on United Nations Economic Commission for Europe (2009) framing of water adaptation responses, the IPCC (2018) framing of adaptation options and also how adaptation responses were reported in the source documents used in this review.

The necessity to consider the role of IK and LK systems in climate adaptation was established in the IPCC-AR5 (IPCC, 2014) citing the lack thereof in previous IPCC Assessments (Ford et al., 2016). The IPCC AR6 Special Reports framed how crucial IK and LK was to climate adaptation especially for regions like Africa, and the importance of IK and LK in knowledge co-production for effective climate adaptation across sectors and regions (Abram et al., 2019). Articles that were included in the IK and LK assessment were selected based on these criteria: articles that include specific words - "indigenous knowledge", "local knowledge", "traditional knowledge", "traditional ecological knowledge", "local or traditional institutions" in the article text linked to adaptation responses implemented or in specific adaptation responses. This framing was based on IPCC framing of the IK and LK systems and practices for climate 
change adaptation in AR6 (Abram et al., 2019). Although useful for clarity in discussion, the IPCC definitions of IK and LK are not commonly used in the African literature on climate change adaptation. In the latter case, IK and LK are commonly collapsed into terms like 'traditional knowledge', 'indigenous knowledge systems', or 'local and indigenous knowledge' where the IPCC distinction is lost or considered by this study as too strict for the African context where notions of indigeneity can be problematic. The IPCC's four evidence levels: strong, high, medium, and low are used throughout the study to describe the evidence levels for both water adaptation responses and IK and LK in the articles across Africa subregions. The evidence levels used were based on guidance provided for IPCC-AR5 assessment (Mastrandrea et al., 2011) (Supplementary Material 2 - SM2. Table 7). Our analysis captured five African regions as used by the IPCC Working Group II - north, southern, west, central, and east Africa. Islands states of Africa were excluded as they are covered under Small Island states in the IPCC-AR6.

\subsection{Data extraction.}

Data extraction in GAMI was guided by an adaptation typology designed to characterize who is responding, what responses are being observed, what the extent of the adaptation-related response is and whether adaptation-related responses are reducing vulnerability and/or risk. A detailed codebook for data extraction is available in the Supplemental Material of Berrang-Ford, Siders, et al. (2021b). The screening of adaptation responses for this review used the filter selection in excel and content analysis in Nvivo 12 following the criteria for systematic reviews in Vaismoradi et al. (2013). Key word analysis - water on sector analysis + specific water adaptation responses as indicated in the Sect. 2.1 (framing of water adaptation responses), e.g., irrigation, water harvesting, water conservation, and water management. For assessing the role of IK and LK, we further developed extension codes to the existing GAMI codes (SM3 Table 10) attributing the nature and form of IK and LK based on approach sets by Petzold et al. (2020) for systematic mapping of indigenous and local knowledge.

\subsection{Analysis of water adaptation responses and role of IK and LK}

We performed qualitative assessments through content analysis of adaptation responses text following the procedure in Vaismoradi et al. (2013) in Nvivo 12. Based on the framing of water adaptation responses presented in Sect. 2.1, we developed five categories of water adaptation responses; water adaptation responses in agriculture, domestic and potable water management responses, ecosystembased responses, grey infrastructure development responses and policy, strategy and enabling conditions responses. Water adaptation response types were grouped for adaptation category.

The attributes of IK and LK were adapted from Petzold et al. (2020) (see SM3 Table 10 on the definition of attributes of IK and LK in the articles). The interactions of local and indigenous people with other adaptation actors (local government, national government, civil society, multilateral organisations) were assessed to ascertain the level of inclusion and influence of local people in both planning and implementation of adaptation responses. The review further linked risk reduction in articles with evidence of indigenous and local knowledge to elicit efficacy of the IK and LK. 


\subsection{IK and LK and African governments NDCs.}

Finally, to assess the role of African governments on framing the water sector adaptation to climate risks and the inclusion of IK and LK in adaptation planning by governments, thematic content analysis of the first NDCs pledges submitted by African governments (2015-2019) to UNFCCC was done using the approach sets in Vaismoradi et al. $(2013 ; 2016)$. The NDCs embody efforts by each country to reduce national emissions and adapt to the impacts of climate change. Our assessment focused on water sector adaptation targets under the adaptation theme per country and whether IK and LK was integrated in longterm adaptation plans (see SM5). Fifty-two iNDCs were retrieved, but only 36 were considered (those submitted in English). NDCs submitted in Spanish and French languages were excluded due to lack of French and Spanish speakers among the author team, also NDCs submitted by small island Africa states were removed because we followed the AR6 five Africa regions (see Sect. 2.1).

\subsection{Limitations}

The GAMI dataset used does not consider grey literature such as government reports, policies, and patents including the National Adaptation Plans of Actions (NAPA), country's climate change adaptation strategies as well as relevant multilateral organisation reports - the UN, United Nations Environment Programme (adaptation gap reports), World Bank, Global Environment Facility, Green Climate Fund. While GAMI provides an unmatched quantity of literature on adaptation, we acknowledge that considering other reports from grey sources could provide further information views such as country level adaptation and specific measures. These reports contain important information on country level adaptation and specific measures that will complement the assessment of scientific literature here. Future studies should consider other sources of data such as grey literature to complement assessment of the scientific literature.

\section{Results}

Analysis of 570 articles on climate change adaptation in Africa identified the range of sectors within which human responses to climate change have been recorded in the peer reviewed literature. Analysis of adaptation responses identified 200 articles that had at least one water adaptation response implemented across sectors. Of the 200 articles with observed water adaptation responses to climate change, $36.5 \%$ had evidence of IK and LK influence, of which $67.1 \%$ of IK and LK papers provide evidence of risk reduction. Key actors and attributes of IK and LK are identified, together with gaps in both. Finally, given the role of IK and LK in water adaptation responses, analysis of the iNDCs highlights the lack of consideration of IK and LK by African governments in adaptation planning. 


\subsection{The geographical distribution of the evidence of water adaptation responses and IK and LK.}

The majority of the adaptation measures were responding to droughts (76.5\%) and precipitation variability (63.5\%) (Figure 2). The articles with water adaptation responses were distributed among 31 African countries (Figure 2). Southern, east, and west Africa have high evidence for both water adaptation responses and water adaptation measures influenced by IK and LK. There is low evidence in central and north African regions. Ethiopia had the highest evidence of water adaptation responses followed by Ghana and Kenya, respectively. South Africa, Nigeria, Tanzania, Zimbabwe, and Uganda had medium evidence with article range between 9 and 19 articles. There is high evidence of the use of IK and LK in Ghana, Kenya, and Zimbabwe (Figure 2). Zimbabwe record the highest number of articles with IK and LK (77.8\%) - relative of the water adaptation articles, followed by Ghana (53.6\%), Kenya (46.2\%) and South Africa with $31.3 \%$. According to response types, many of the adaptation responses were behavioural/ cultural and technological/ Infrastructure (Table 1). Linking the adaptation response types with IK and LK, results show that $92 \%$ of the IK and LK influenced adaptation responses were associated with behavioural/cultural responses followed by technological/ infrastructure (76\%) and ecosystem-based responses (68\%). Technological responses were more linked to how communities use IK and LK to implement local irrigation practices during periods of water stress and off season. Institutional responses were the least with $33.3 \%$ of the responses linked to institutional.

Table 1: Types of adaptation responses recorded in the literature.

\begin{tabular}{|l|l|l|l|l|}
\hline Adaptation responses & Count & Proportion & IK and LK associated & Proportion \\
\hline Behavioural/cultural & 169 & $81 \%$ & 69 & $92 \%$ \\
\hline Ecosystem-based & 141 & $70.1 \%$ & 51 & $68 \%$ \\
\hline Institutional & 60 & $29.9 \%$ & 25 & $33.3 \%$ \\
\hline Technological/infrastructure & 160 & 79.6 & 57 & $76 \%$ \\
\hline & $n=200$ & & $n=73$ & \\
\hline
\end{tabular}

\subsection{The distribution of water adaptation response types}

We identified 18 types of water adaptation responses implemented in Africa across sectors (Table 2). The geographic distribution of these water adaptation responses shows that literature on water sector adaptation in Africa is not evenly distributed across the continent and not evenly distributed across different types of adaptation. The majority of the articles were drawn from literatures covering food, fibre, 
and other ecosystems (73\%) and poverty, livelihoods, and sustainable development sectors (64.5\%) (SM 2 Table 9). Irrigation is the most implemented response recorded in $47 \%$ of the articles. This includes the increased use of water saving irrigation methods such as drip irrigation in some parts of north Africa. Rainwater harvesting was the second most implemented response (36.3\%). Rainwater harvesting was implemented through a diversity of technologies, which include in-situ measures, rooftop water collection, valley tanks, pitting, contour bunds, rooftop harvesting for potable water, diversion weirs for irrigation, check-dam ponds, dugouts, and shallow wells. Water conservation techniques in the agriculture sector was the third highest response recorded (31.8\%). Other measures with medium evidence of implementation include agroforestry measures to increase infiltration and groundwater recharge through forestry and catchment management. Details of the geographic distribution of specific water adaptation responses per country are presented in figure 1 of the SM4.

Table 2. Assessment of the water adaptation responses across sub-regions of Africa and the evidence of IK and LK per adaptation response. 


\begin{tabular}{|c|c|c|c|c|c|c|c|c|c|c|c|c|}
\hline \multirow{2}{*}{ Category } & \multirow{2}{*}{ Specific water adaptation responses } & \multicolumn{5}{|c|}{ Africa regions } & \multirow{2}{*}{ Total } & \multicolumn{5}{|c|}{ IK and LK } \\
\hline & & SA & EA & WA & NA & CA & & SA & EA & WA & NA & CA \\
\hline \multirow{5}{*}{$\begin{array}{l}\text { Water adaptation } \\
\text { responses in } \\
\text { agriculture }\end{array}$} & $\begin{array}{l}\text { Irrigation including responses to reduce water use through } \\
\text { technological interventions e.g., change from surface to drip } \\
\text { irrigation }\end{array}$ & 16 & 37 & 33 & 6 & 2 & 94 & 9 & 8 & 8 & 1 & 2 \\
\hline & $\begin{array}{l}\text { Rainwater/water harvesting (field in-situ responses - contours, } \\
\text { semi-circular bunds, strip catchment, pitting -zai pits etc) }\end{array}$ & 17 & 26 & 7 & 0 & 0 & 50 & 4 & 12 & 5 & 0 & 0 \\
\hline & $\begin{array}{l}\text { Soll and water conservation (e.g., ditches, terracing, soil -water } \\
\text { moisture retention strategies, moisture conservation farming) }\end{array}$ & 9 & 24 & 28 & 3 & 1 & 65 & 1 & 10 & 10 & 0 & 1 \\
\hline & Increased groundwater abstraction for irfrigation, livestock - wells & 4 & 5 & 1 & 2 & 0 & 12 & 2 & 2 & 0 & 1 & 0 \\
\hline & Flood water control (flood water harvesting, diverting, drainage) & 3 & 2 & 2 & 0 & 1 & 8 & 1 & 0 & 0 & 0 & 0 \\
\hline \multirow{7}{*}{$\begin{array}{l}\text { Domestic \& } \\
\text { potable water } \\
\text { management } \\
\text { adaptation } \\
\text { responses }\end{array}$} & $\begin{array}{l}\text { Rainwater harvesting include increased household bulk water } \\
\text { storage }\end{array}$ & 8 & 11 & 4 & 0 & 0 & 23 & 4 & 2 & 0 & 0 & 0 \\
\hline & $\begin{array}{l}\text { Household level water management and resilience (water saving } \\
\text { responses, reduce water usage, improve usage, improve storage } \\
\text { during droughts and floods) }\end{array}$ & 7 & 5 & 2 & 2 & 0 & 16 & 3 & 2 & 1 & 1 & 0 \\
\hline & $\begin{array}{l}\text { Water markets - vending (community level water transfers), } \\
\text { recycling. re-use }\end{array}$ & 1 & 2 & 4 & 1 & 0 & 8 & 1 & 1 & 1 & 0 & 0 \\
\hline & $\begin{array}{l}\text { Increased groundwater abstraction for domestic purposes - mainly } \\
\text { borehole drilling and deepening of wels }\end{array}$ & 6 & 1 & 0 & 0 & 0 & 7 & 2 & 2 & 0 & 0 & 0 \\
\hline & Improve drainage systems for flood water removal & 4 & 2 & 3 & 0 & 0 & 9 & 1 & 1 & 1 & 0 & $\mathbf{0}$ \\
\hline & Municipal level water supply rationing & 3 & 1 & 0 & 0 & 0 & 4 & 0 & 0 & 0 & 0 & 0 \\
\hline & $\begin{array}{l}\text { Flood relief responses e.g., construction of raised ground platforms } \\
\text { for houses located in flood plains, sandbags, permanent or } \\
\text { temporary to less flood vulnerable areas }\end{array}$ & 6 & 4 & 4 & 0 & 0 & 13 & 1 & 1 & 1 & 0 & 0 \\
\hline \multirow{2}{*}{$\begin{array}{l}\text { Ecosystem based } \\
\text { responses }\end{array}$} & Agroforestry to improve infiltsation for groundwater recharge & 6 & 11 & 20 & 1 & 2 & 40 & 1 & 6 & 7 & 0 & 2 \\
\hline & $\begin{array}{l}\text { Protection of watersheds, catchment management, wetland } \\
\text { restoration, mulching to increase, infiltration, soil moisture and } \\
\text { groundwater recharge }\end{array}$ & 7 & 8 & 4 & 0 & 0 & 19 & 3 & 5 & 4 & 0 & 0 \\
\hline $\begin{array}{l}\text { Grey } \\
\text { infrastructure } \\
\text { development }\end{array}$ & $\begin{array}{l}\text { Increase reservoir storage through dam construction of smal, } \\
\text { medium \& large-scale (for water supply - agriculture \& potable) } \\
\text { and flood control dams, weir construction }\end{array}$ & 10 & 9 & 2 & 0 & 1 & 21 & 0 & 2 & 1 & 0 & 1 \\
\hline \multirow{3}{*}{$\begin{array}{l}\text { Policy, strategy } \\
\text { and enabling } \\
\text { conditions } \\
\text { responses }\end{array}$} & $\begin{array}{l}\text { Introduction of a policy, improving enabling environment for water } \\
\text { management under climate stressed shortages, flood management } \\
\text { plans, strategies, and other governance mechanisms }\end{array}$ & 2 & 1 & 1 & 2 & 0 & 7 & 0 & 0 & 0 & 0 & 0 \\
\hline & Implementation of IWRM plans & 1 & 0 & 0 & 0 & 0 & 1 & 0 & 0 & 0 & 0 & 0 \\
\hline & Effective water tariffing & 1 & 0 & 0 & 0 & 0 & 1 & 0 & 0 & 0 & 0 & 0 \\
\hline
\end{tabular}

"SA $=$ southern Africa; $E A=$ east Africa; $C A=$ central Africa; WA $=$ west Africa; $N A=$ north Africa.

Evidence of water adaptation responses
\begin{tabular}{|l|}
\hline Strong evidence \\
\hline High evidence \\
\hline Medfum evidence \\
\hline Low evidence \\
\hline No data \\
\hline
\end{tabular}

\begin{tabular}{l} 
Evidence of IK and LK per adaptation responses \\
\hline Strong evidence \\
\hline High evidence \\
\hline Medium evidence \\
\hline Low evidence \\
\hline No data \\
\hline
\end{tabular}

* The figures are indicating the number of articles per adaptation responses per region. The total column represents the summation of the articles for the whole of Africa per adaptation measure.

\subsection{IK and LK roles in water adaptation responses.}


Out of the 200 articles with water adaptation responses, $36.5 \%$ (73) of the articles had evidence of the use of IK and LK in the implementation of the adaptation responses. Attribution of the IK and LK used by communities in water-climate change adaptation shows that $45.3 \%$ of this knowledge was factual knowledge about the use of the environment and $30.1 \%$ of the knowledge was factual knowledge about the environment and environmental changes (Table 3) which both triggered behavioural changes, shift in practices and technological interventions using indigenous knowledge by farmers and communities. Of the articles with evidence of IK and LK use, $67.1 \%$ recorded risk reduction compared to $60.6 \%$ for the articles without IK and LK (Table 4).

Table 3. Attributes of IK and LK used in the adaptation responses implemented in Africa.

\begin{tabular}{|c|c|c|c|}
\hline $\begin{array}{l}\text { Attributes of } \\
\text { indigenous } \\
\text { knowledge }\end{array}$ & $\begin{array}{l}\text { Number of } \\
\text { Publications }\end{array}$ & Example & $\begin{array}{l}\text { Representative } \\
\text { study }\end{array}$ \\
\hline \multirow{2}{*}{$\begin{array}{l}\text { Factual } \\
\text { knowledge about the } \\
\text { environment and } \\
\text { environmental } \\
\text { changes }\end{array}$} & \multirow[t]{2}{*}{47} & $\begin{array}{l}\text { Early warnings based on observation of the environment and natural } \\
\text { phenomena (water wells) in Ramarumo, Kubake and Malumeng } \\
\text { communities in Lesotho }\end{array}$ & $\begin{array}{l}\text { (Kamara et al., } \\
\text { 2019) }\end{array}$ \\
\hline & & $\begin{array}{l}\text { Pollution of open water sources from strong winds gust and drying of } \\
\text { water wells for disaster (droughts) early warning in Swaziland and } \\
\text { Lesotho }\end{array}$ & $\begin{array}{l}\text { (Kamara et al., } \\
\text { 2019) }\end{array}$ \\
\hline \multirow[t]{3}{*}{$\begin{array}{l}\text { Factual knowledge } \\
\text { about the use of the } \\
\text { environment }\end{array}$} & \multirow[t]{3}{*}{49} & $\begin{array}{l}\text { Indigenous soil and water conservation responses in Atankwidi basin, } \\
\text { Ghana - communities use indigenous organic matter (Nandeene, } \\
\text { Tampugere, Na'ambea) to improve soil fertility thus increases the } \\
\text { water retention capacity of their soils. }\end{array}$ & $\begin{array}{l}\text { (Derbile, } \\
\text { 2013) }\end{array}$ \\
\hline & & Use traditional knowledge for water conservation in Ghana. & $\begin{array}{l}\text { (Ahmed et al., } \\
\text { 2016) }\end{array}$ \\
\hline & & Traditional and indigenous irrigation methods. & $\begin{array}{l}\text { (Ologeh et al., } \\
\text { 2018) }\end{array}$ \\
\hline Cultural values & 6 & $\begin{array}{l}\text { The Zunde raMambo ('the chief's granary) - a traditional social } \\
\text { security arrangement designed to protect vulnerable groups and those } \\
\text { affected by disasters such as floods and drought practiced by local and } \\
\text { indigenous people in Muzarabani, Zimbabwe. }\end{array}$ & $\begin{array}{l}\text { (Mavhura, } \\
\text { 2017a; } \\
\text { Mavhura, } \\
\text { 2017b) }\end{array}$ \\
\hline \multirow[t]{3}{*}{$\begin{array}{l}\text { Governance and } \\
\text { social capital }\end{array}$} & \multirow[t]{3}{*}{17} & $\begin{array}{l}\text { Communities use social networking to build safety nets for adaptation } \\
\text { in Ghana. }\end{array}$ & $\begin{array}{l}\text { (Ahmed et al., } \\
\text { 2016) }\end{array}$ \\
\hline & & $\begin{array}{l}\text { Use of societal customs, traditions, rules, laws to increase societal } \\
\text { resilience to water stress caused by droughts in Swaziland and } \\
\text { Lesotho. }\end{array}$ & $\begin{array}{l}\text { (Kamara et al., } \\
\text { 2019) }\end{array}$ \\
\hline & & $\begin{array}{l}\text { Traditional authorities assign higher ground areas that people gather } \\
\text { during floods in Kenya. }\end{array}$ & $\begin{array}{l}\text { (Thorn et al., } \\
\text { 2015) }\end{array}$ \\
\hline Others & 4 & Rain seeking ceremonies in Zimbabwe. & $\begin{array}{l}\text { (Bhatasara, } \\
\text { 2017) }\end{array}$ \\
\hline
\end{tabular}

$n=73$.

Table 4. Risk reduction for adaptation responses with evidence of IK and LK vs adaptation responses without evidence of IK and LK. 


\begin{tabular}{|l|c|c|l|}
\hline \multirow{2}{*}{ Category } & \multicolumn{2}{|l|}{ Evidence of risk reduction } & Number of publications \\
\cline { 2 - 4 } & Yes & No & \\
\hline Evidence of indigenous and local knowledge & $49(67.1 \%)$ & $24(32.9 \%)$ & $n=73$ \\
\hline No evidence of indigenous and local knowledge & $77(60.6 \%)$ & $49(39.4 \%)$ & $n=127$ \\
\hline
\end{tabular}

\subsection{The role of governments on framing water sector adaptation}

More than $90 \%$ of the African governments have clear water sector adaptation targets. Table 5 shows a breakdown of the water sector targets in iNDCs submitted by African governments and the acknowledgement of IK and LK in planned adaptation. Only $10.4 \%$ of the African governments (Benin, Burkina Faso, Somalia, South Africa, and Zimbabwe) acknowledged and included IK and LK in their longterm adaptation planning. About 33.3\% of the African governments are planning to expand irrigation capacity through increasing irrigation infrastructure and improve efficiency of irrigation systems, $72 \%$ of the governments are prioritising investments in grey infrastructure development to increase reservoir capacity and storage of rainfall through rainwater harvesting, large scale multipurpose dams, reservoir improvement and monitoring. 53\% of the countries target improved water sector governance systems through policy, integrated management plans, strategies, sustainable water resources development that promote ecosystem-based management responses and other soft path adaptation responses.

[Please see the supplementary files section to view Table 5.]

\section{Discussion}

This review identified and mapped the evidence of water adaptation responses implemented in Africa in peer-reviewed literature recorded between 2013-2019, highlighting those influenced by IK and LK. Consistent with previous studies, droughts and precipitation variability were the most frequently responded to climate hazards in Africa (Niang et al., 2014; Berrang-Ford et al., 2021b) (see Figure 2). Overall, there is high evidence of water adaptation responses implemented in east, west and southern African regions and little evidence in north and central Africa. These results are consistent with the adaptation feasibility assessment of Williams et al. (2021). Communities are using IK and LK to inform decisions influencing the implementation of the adaptation responses. Of the water adaptation responses, high evidence of IK and LK influence was identified in Ghana for west Africa, Zimbabwe and South Africa for southern Africa and Kenya in west Africa. Knowledge on scalability of these responses to regional scale is not yet established partly due to the early stage of implementation of most adaptation actions in Africa (Berrang-Ford et al., 2021b). Given the proposed increase of multilateral funding for adaptation 2020-2030 from the four major climate and development funders - Green Climate Fund, 
Adaptation Fund, Global Environment Facility and the International Climate Initiative, there is a window of opportunity for these measures to be scaled up through better integration of IK and LK (United Nations Environment Programme, 2021).

Most of the water adaptation responses are water management actions in agriculture that are linked to farmers' and communities' agronomic practices. There is consistency between our results on IK and LK linked adaptation response type (Table 1) and IK and LK attribution (Table 3) where factual knowledge about the use of the environment records the highest. We find that where African communities are applying IK and LK, that this leads to behavioural and cultural changes in water use, management and conservation, which is vital for climate risk adaptation particularly during drought and floods. A third of the water adaptation response articles had evidence of IK and LK use in the implementation of the adaptation responses. Most of the IK and LK evidence is distributed in Ghana, Kenya, and Zimbabwe extending the findings of Petzold et al. (2020) who observed high evidence of IK and LK in climate change adaptation in Zimbabwe and Kenya. IK and LK exists in various forms with the majority being factual knowledge about the use of environment, followed by factual knowledge on the environment and environmental change, cultural values and the governance and social capital. Local institutions (local governance system) are recorded as informal institutions in literature despite these channels being responsible for stricter measures or by laws, which they put in place to check both social and environmental controls at local level in communities (Abass et al., 2018).

Adaptation responses with IK and LK over this reference period of 2014-2020, record higher evidence of risk reduction compared to responses without IK and LK. Risk reduction in this study was not thoroughly assessed, both qualitatively and quantitatively. However, the results form the basis to further comprehensively assess risk reduction for IK and LK adaptation response type. Understanding the extent to which IK and LK adaptation response contributes to climate risk reduction is critical to evaluate effectiveness of the responses to reduce climate risks, which is the aim of climate adaptation (BerrangFord et al., 2021b).

In the Atankwidi basin, in north-east Ghana, indigenous knowledge systems (indigenous water conservation measures) for climate adaptation record dual moderating effects on reducing the vulnerability to droughts (Derbile, 2013). Traditional adaptation measures practiced by local communities provide both temporary and long-time solutions; for example, stone terraces to harvest water for irrigation have been used for 19 years, on average, by households to adapt to changing micro-environments in Semien Mountains of Ethiopia (Yohannes et al., 2019). This illustrates how communities have developed trust in such measures; however, it is important to establish whether these long-term practiced measures are reducing the climate risks, or whether they are creating culture lock-ins that are increasing their vulnerability. Most of the adaptation responses in literature are highly localised implemented to address specific situations. Scaling up of some of the knowledge and creating platforms to advance the sharing of the knowledge is key to ensure a regional transformative adaptation process. Passing on of this knowledge to following generations would also ensure sustainability of these responses; for example, 
communities in Kenya have passed on traditional methods of responding to floods through many generations and these strategies are integrated into daily praxis (Thorn et al., 2015).

\subsection{Water adaptation responses and IK and LK}

Irrigation methods is the most commonly reported adaptation response and implemented by most communities and farmers across African countries. This includes expanding the irrigation capacity in Kenya, Zimbabwe, Zambia, Ethiopia and improving irrigation water use efficiency through adoption of efficient irrigation systems and local irrigation water saving techniques such as drip irrigation using local initiatives in countries such as Morocco (Aziz and Sadok, 2015), South Africa (Elum et al., 2017) and Uganda (Nakabugo et al., 2019). If scaled, improvements in irrigation efficiency in Africa's agriculture system has the potential to reduce water used by the agriculture sector especially in water stressed regions. This can address some maladaptation concerns linked to the increased use of irrigation such as the excessive abstraction of limited water resources. As many African governments pledged iNDCs to expand irrigation, the shift from high water demand irrigation system to efficient, water saving irrigation system that can adjust to future water stress is key. Government's role in promoting adoption of such technology is important; this can be through implementation of irrigation policies that enable the adoption of water saving irrigation technology and farmer support.

In many cases, farmers and communities are using indigenous knowledge to apply traditional irrigation methods during the dry season or when there is limited supply of water e.g. use of post-inundation residual moisture as natural irrigation Zimbabwe (Mavhura, 2017a), cultivating on stream banks to increase access to irrigation water e.g. indigenous swamp farming in Nigeria (Ologeh et al., 2018), floodplain cultivation in Zimbabwe (Mavhura, 2017a), indigenous cultivation in wetlands to increase moisture availability in Nigeria (Ajayi, 2014). However, some of these water adaptation options that are working today presents maladaptation threats over-long term, e.g., continuous water harvesting in a catchment may reduce water supply risk to the communities upstream but may have negative outcomes to the downstream communities (Singh, 2018; Eriksen et al., 2021). Also, stream bank cultivation will increase the vulnerability of crops to future river flooding, wetlands often act natural barriers to flooding therefore cultivation in such areas increases flooding chances to downstream areas.

As many regions in Africa are experiencing water scarcity and insecurity linked to climate change, regions and countries are exploring alternative water sources informed by IK and LK. For example, during siting and accessing groundwater to increase their access to water resource, e.g., in Tanzania communities are using indigenous knowledge for groundwater exploring and management for drinking water that allow them to access deep aquifers (Shemsanga et al., 2018). The accessed water also used to supplement agricultural activities through indigenous means of irrigating crop fields as practiced in Ghana (Abass et 
al., 2018). In Dupong communities in Ghana, this extended to community members who, through their indigenous and local weather predictions, use less water which enabled them to save enough water for other equally relevant uses during droughts and limited supply (Opare, 2018). Also, through digging watering points by pastoralists during periods of reduced water supply in Tanzania (Sangeda et al., 2013) and increasing protected well water use to improve domestic water supply especially in Zimbabwean urban areas practicing strict water rationing (Chanza, 2017) as well as in rural areas (Kanda et al., 2017).

Local communities and indigenous people are using local and indigenous knowledge on water management i.e., collection and storage during seasons. This involved rain season water harvesting through indigenous means for both agricultural purposes (Mugi-Ngenga et al., 2016; Nakabugo et al., 2019) such as irrigation (Abass et al., 2018), water for livestock by pastoralists (Filho et al., 2017; Mashizha, 2019), and to increase domestic water supply by diversifying sources of potable water (Nakabugo et al., 2019). Various initiatives which are influenced by IK and LK implemented to harvest rainwater include the use of valley tanks in Uganda (Nakabugo et al., 2019), the use of water pans in Kenya (Mugi-Ngenga et al., 2016), zai pits, semi-circular bunds, and small dams in Kenya (Recha et al., 2014), contour bunds in Nigeria (Ajayi, 2015), digging dead end contours in Zimbabwe (Mupakati and Tanyanyiwa, 2017). All these measures were linked to the locals' and indigenous people's factual knowledge about the environment and environmental changes and factual knowledge about the use of the environment. Water harvesting has increased communities' resilience to water stress conditions by supplementing water for irrigation during rainy and dry seasons, thus improving food security. However, these were mostly seasonal storage options that can be badly affected successive years of droughts as demonstrated in Ghana where ponds used by farmers to harvest water to support agricultural activities dry up easily after rainy seasons (Abass et al., 2018). Further, the scalability of some of water harvesting technologies and practices is yet to be established. For potable water harvesting, communities used various technologies and initiatives among the digging of pits that provide additional water to households in Ghana (Opare, 2018), hand-dug wells in Ethiopia (Yohannes et al., 2019). Potable rainwater harvesting improves household water security by supplementing existing water sources to address the water scarcity linked by climate stress (Ofoegbu et al., 2016).

Many communities in east and southern Africa are implementing water conservation practices. These include both communities' behavioural and cultural changes and technological and infrastructure interventions related to farmers' and household agronomic practices that save water, mostly green water. Most of the water conservation technology and practices include terracing technology in Ethiopia (Cholo et al., 2018), communities' construction of trenches for water management in Ghana and Uganda (Jost et al., 2015). Local and indigenous groups extend these practices to broader catchment management practices applying a spectrum of knowledge and initiatives. These responses improve catchment storage; the review shows that several communities in Africa are implementing ecosystem-based management responses, such as agroforestry using indigenous species, to reduce erosion that improved water infiltration and groundwater recharge (Aimé et al., 2016; Sanogo et al., 2016; Tambo and Wünscher, 2017; 
Awazi et al., 2019). Also, communities use traditional knowledge to manage and conserve water during water stressed seasons (Ahmed et al., 2016).

Several regions across Africa are implementing local level water management initiatives using their traditional knowledge to manage scarce resources during periods of crisis. Some of the water management strategies implemented during droughts and water scarcity include reducing water usage, improve storage, water re-use. Under conditions of limited access to potable water caused by droughts, communities in Benin use indigenous knowledge to treat water to increase drinking water supply (Oyerinde et al., 2017). Communities across Africa use IK and LK to implement watershed management responses to water supply shortages caused by climate seasonal variability. For example, local farmers implement catchment water conservation using local plant varieties in Mutoko, Zimbabwe (Bhatasara, 2017), in Ghana communities minimize deforestation to improve groundwater storage through increased infiltration (Abass et al., 2018).

\subsection{Limits to adaptation on IK and LK use in the water responses}

To determine the sustainability and opportunities of IK and LK use in climate adaptation in Africa, it is important to discuss limits to adaptation associated with IK and LK observed in literature across Africa. $78.1 \%$ of the articles with IK and LK record limits to adaptation. The majority of these limits were linked to lack of financial resources needed for effective adaptation, lack of access to climate information to complement the indigenous and traditional indicators used for early warning systems used by communities. Since most of the IK and LK responses were technological and behavioural/cultural responses (see Table 1), lack of human capacity was one of the main limiting factors in the implementation of labour-intensive irrigation and agriculture water conservation techniques (Yohannes et al., 2019). This is because the responses were implemented at household level relying mostly on family labour. Although these communities have relevant knowledge and practices crucial for climate adaptation, the success of labour-intensive responses depend on the family availability of the labourforce. Due to factors such as the limited financial resources and poverty, they cannot outsource the labour. In some cases, indigenous practices such as Zunde raMambo (the chief's granary) in Zimbabwe help address labour shortages as communities gather to share labour (Mavhura, 2017b) (Mavhura, 2017) in addressing drought effects.

The lack of access to climate information, which is, critical for adaptation planning constrained local and indigenous people (Spear and Chappel, 2018; Sadiq et al., 2019; Williams et al., 2019). Language barriers also hinder the access to climate information for local and indigenous people. A lack of finance was among the important constraints to the implementation of IK and LK practices cited in the 
publications (Abass et al., 2018; Sadiq et al., 2019), this is due to the high cost associated with procurement of equipment that aid the success of the technology (Filho et al., 2017). Gender and cultural norms and traditional practices also hindered the implementation of some water adaptation responses. For example, the capability to collect water from outlying water sources in Ghana encountered social and cultural limitations in communities where women are not allowed to use bicycles to collect water (Opare, 2018).

\subsection{Integrating IK and LK in water sector adaptation.}

Water is the most prioritised sector by African governments for adaptation to climate change. Over $90 \%$ of African countries have water sector targets in their iNDCs. A comparison between water sector adaptation goals in the iNDCs and the evidence of water sector adaptation responses recorded in various African countries shows a link between government policies and how various stakeholders are adapting. For example, many grey water infrastructure goals expressed in the iNDCs (increase water supply, increase irrigation capacity, rainwater harvesting infrastructure) were also the highest recorded water adaptation responses recorded in literature as evidence of how the water sector in Africa is adapting to climate change. This potentially characterises how countries will drive water sector adaptation and the influence of policy on adaptation in Africa. Yet we found IK and LK is barely included in planned adaptation, only $10.4 \%$ of the African governments acknowledge and include IK and LK in planned adaptation. Given the evidence of the high reliance of African communities on IK and LK for water sector adaptation this is a concerning lack of consideration of IK and LK to give effect to planned responses.

The above highlights a gap in academic literature on the role of IK and LK in implementation of adaptation responses and the acknowledgment of this knowledge at policy level by African governments through formal adaptation channels. These shortcomings notwithstanding, evidence of the role IK and LK play in water sector adaptation cautions that planned adaptation in Africa is likely to be more broadly adopted, accepted by communities, and align with cultural norms if IK and LK are included. There is a window for African governments to incorporate IK and LK into national adaptation planning to increase their realisation of the adaptation goals set in the NDCs. The use of multiple sources of knowledge (scientific, and indigenous and local knowledge) is crucial and will enhance transformational adaptation in Africa. This is also key in developing disruptive adaptation responses that effectively address the climate risk in the water sector.

\section{Conclusion}

The evidence of implementation of water adaptation responses to climate risk is growing in Africa. We identified and mapped water adaptation responses implemented across Africa and the role of IK and LK 
in the implementation of these adaptation responses. Irrigation, water conservation (green water), rainwater harvesting and catchment management responses such as the use of ecosystem-based approaches are among the most implemented responses. The evidence of water adaptation responses and IK and LK influence is high in east Africa - Ethiopia, Kenya, Uganda, west Africa - Ghana and Nigeria and in southern Africa - Zimbabwe, South Africa. There is low evidence of water adaptation responses in north and central Africa. Knowledge on the efficacy of these responses and potential maladaptation threats from some of the adaptation practices is not yet established. This is likely because the adaptation in Africa is at the early stage of implementation (Berrang-Ford et al., 2021b). There is a need for a comprehensive approach that assess risk reduction of IK and LK climate change adaptation response type in Africa. Our assessment shows that most of the water adaptation responses are highly localised; therefore, the aspect of scalability of the responses at regional level should be considered carefully. IK and LK in communities is important for water management and initiatives implemented by communities in Africa. However, in the current academic literature, it is evidently viewed as informal knowledge with less value. There is also a lack of coverage and respect of this knowledge in formal climate adaptation channels in African. Analysis of Africa iNDCs showed that IK and LK was barely included in adaptation planning, despite Africa being one of the regions with rich IK and LK practices used for climate change adaptation. We recommend a coordinated approach that integrates multiple knowledge systems including local and indigenous knowledge in adaptation to ensure sustainability of both the current and proposed water adaptation responses in Africa.

\section{Declarations}

\section{Conflict of interest}

None

\section{Funding}

This work was carried out with financial support from the UK Government's Foreign, Commonwealth \& Development Office and the International Development Research Centre, Ottawa, Canada.

\section{List of supplementary material}

The list of supplementary material consists of

1. Definition of the relevant GAMI codes, file with relevant GAMI coded data (excel file) - SM1.

2. Full list of African country covered in this study and the explanation of the evidence levels used SM2.

3. Extension codes developed for articles that had evidence of IK and LK, also excel file for article with IK and LK attribution codes (SM3).

4. Geographic distribution of specific water adaptation responses per country (SM4).

5. iNDCs - List of countries with iNDCs covered in this study and their water adaptation targets (SM5). 


\section{References}

Abass, R., A. Mensah and B. Fosu-Mensah, 2018: The Role of Formal and Informal Institutions in Smallholder Agricultural Adaptation: The Case of Lawra and Nandom Districts, Ghana. West African Journal of Applied Ecology, 26, 56-72.

Abram, N. et al., 2019: Framing and context of the report. In: IPCC Special Report on the Ocean and Cryosphere in a Changing Climate [H.-O. Pörtner, D. C. R., V. Masson-Delmotte, P. Zhai, M. Tignor, E. Poloczanska, K. Mintenbeck, A. Alegría, M. Nicolai, A. Okem, J. Petzold, B. Rama, N.M. Weyer (ed.)]. In press pp. Available at:

https://www.ipcc.ch/site/assets/uploads/sites/3/2019/11/05_SROCC_Ch01_FINAL.pdf.

Ahmed, A. et al., 2016: Adaptation to climate change or non-climatic stressors in semi-arid regions? Evidence of gender differentiation in three agrarian districts of Ghana. Environmental Development, 20, 45-58, doi:10.1016/j.envdev.2016.08.002.

Aimé, F. R. et al., 2016: Adaptations of the Agricultural Calendar and Agricultural Techniques to Climate Change in the Highlands of Cameroon. In: Agricultural Adaptation to Climate Change [Bryant C., S. M., Délusca K. (ed.)]. Springer, pp. 199-224.

Ajayi, J. O., 2014: Awareness of climate change and implications for attaining the Millennium Development Goals (MDGs) in Niger Delta Region of Nigeria. Agris on-line Papers in Economics and Informatics, 6(1), 3-11, doi:http://dx.doi.org/10.22004/ag.econ.166520.

Ajayi, J. O., 2015: Effects of Climate Change on the Production and Profitability of Cassava in the Niger Delta Region of Nigeria. Agris on-line Papers in Economics and Informatics, 7(2), 3-11, doi:10.7160/aol.2015.070201.

Awazi, N. P., M. N. Tchamba and T. M. L. Avana, 2019: Climate change resiliency choices of small-scale farmers in Cameroon: determinants and policy implications. Journal of Environmental Management, 250, doi:10.1016/j.jenvman.2019.109560.

Aziz, L. and W. Sadok, 2015: Strategies used by the saffron producers of Taliouine (Morocco) to adapt to climate change. Journal of Alpine Research,(103-2), 0-13, doi:10.4000/rga.2902.

Berrang-Ford, L. et al., 2021a: The Global Adaptation Mapping Initiative (GAMI): Part 1 - Introduction and overview of methods. Nature Protocol Exchange, doi:10.21203/rs.3.pex-1240/v1.

Berrang-Ford, L. et al., 2021b: A systematic global stocktake of evidence on human adaptation to climate change. Nature Climate Change, doi:https://doi.org/10.21203/rs.3.rs-100873/v1.

Bhatasara, S., 2017: Towards a Sociology of Adaptation to Rainfall Variability in Rural Zimbabwe: The Case of Charewa in Mutoko. Fudan Journal of the Humanities and Social Sciences, 10(4), 547-568, doi:10.1007/s40647-017-0177-8. 
Chanza, N., 2017: Limits to climate change adaptation in Zimbabwe: Insights, experiences and lessons. In: Limits to Climate Change Adaptation [Leal Filho, W. and J. Nalau (eds.)]. Springer International Publishing, pp. 109-127.

Cholo, T., L. Fleskens, D. Sietz and J. Peerlings, 2018: Is Land Fragmentation Facilitating or Obstructing Adoption of Climate Adaptation Measures in Ethiopia? Sustainability, 10(7), 2120, doi:10.3390/su10072120.

Derbile, E. K., 2013: Reducing vulnerability of rain-fed agriculture to drought through indigenous knowledge systems in north-eastern Ghana. International Journal of Climate Change Strategies and Management, 5(1), 71-94, doi:10.1108/17568691311299372.

Elum, Z. A., D. M. Modise and A. Marr, 2017: Farmer's perception of climate change and responsive strategies in three selected provinces of South Africa. Climate Risk Management, 16, 246-257, doi:10.1016/j.crm.2016.11.001.

Eriksen, S. et al., 2021: Adaptation interventions and their effect on vulnerability in developing countries: Help, hindrance or irrelevance? World Development, 141, doi:10.1016/j.worlddev.2020.105383.

Filho, W. L. et al., 2017: Climate change responses among the Maasai Community in Kenya. Climatic Change, 145(1-2), 71-83, doi:10.1007/s10584-017-2087-9.

Fischer, A. P. et al., 2021: The Global Adaptation Mapping Initiative (GAMI): Part 2 - Screening protocol. Nature Protocol Exchange, doi:10.21203/rs.3.pex-1241/v1.

Ford, J. D. et al., 2016: Including indigenous knowledge and experience in IPCC assessment reports. Nature Climate Change, 6(4), 349-353, doi:https://doi.org/10.1038/nclimate2954.

Global Risk Report, 2021. World Economic Forum, Geneva. Available at:

https://reports.weforum.org/global-risks-report-2021/.

Global Water Partnership, 2018: Preparing to Adapt: The Untold Story of Water in Climate Change Adaptation Processes. Stockholm, 1-20 pp. Available at: https://www.gwp.org/globalassets/global/events/cop24/gwp-ndc-report.pdf.

Haddaway, N. R., B. Macura, P. Whaley and A. S. Pullin, 2018: ROSES Reporting standards for Systematic Evidence Syntheses: Pro forma, flow-diagram and descriptive summary of the plan and conduct of environmental systematic reviews and systematic maps. Environmental Evidence, 7(1), 4-11, doi:10.1186/s13750-018-0121-7.

IPCC, 2014: Climate Change 2014: Impacts, Adaptation, and Vulnerability. Part A: Global and Sectoral Aspects. Contribution of Working Group II to the Fifth Assessment Report of the Intergovernmental Panel on Climate Change [Field, C. B., V.R. Barros, D.J. Dokken, K.J. Mach, M.D. Mastrandrea, T.E. Bilir, M. Chatterjee, K.L. Ebi, Y.O. Estrada, R.C. Genova, B. Girma, E.S. Kissel, A.N. Levy, S. MacCracken, P.R. 
Mastrandrea, and L.L.White (ed.)]. Cambridge University Press, Cambridge, United Kingdom and New York, NY, USA, 1132 pp. Available at: https://www.ipcc.ch/site/assets/uploads/2018/02/WGIIAR5PartA_FINAL.pdf.

IPCC, 2018: In: Global Warming of $1.5^{\circ} \mathrm{C}$. An IPCC Special Report on the impacts of global warming of $1.5^{\circ} \mathrm{C}$ above pre-industrial levels and related global greenhouse gas emission pathways, in the context of strengthening the global response to the threat of climate change, sustainable development, and efforts to eradicate poverty [Matthews, J. B. R. M.-D., V., P. Zhai, H.-O. Pörtner, D. Roberts, J. Skea, P.R. Shukla, A. Pirani, W. Moufouma-Okia, C. Péan, R. Pidcock, S. Connors, J.B.R. Matthews, Y. Chen, X. Zhou, M.I. Gomis, E. Lonnoy, T. Maycock, M. Tignor, and T. Waterfield (ed.)]. Available at: https://www.ipcc.ch/site/assets/uploads/sites/2/2019/06/SR15_AnnexI_Glossary.pdf.

IPCC, 2019a: Climate Change and Land: an IPCC special report on climate change, desertification, land degradation, sustainable land management, food security, and greenhouse gas fluxes in terrestrial ecosystems [Skea, J., E. Calvo Buendia, V. Masson-Delmotte, H. O. Pörtner, D. C. Roberts, P. Zhai, R. Slade, S. Connors, R. van Diemen, M. Ferrat, E. Haughey, S. Luz, S. Neogi, M. Pathak, J. Petzold, J. Portugal Pereira, P. Vyas, E. Huntley, K. Kissick, M. Belkacemi and J. Malley (eds.)]. In press, Shukla, P. R. Available at: https://www.ipcc.ch/srccl-report-download-page/.

IPCC, 2019b: Global Warming of $1.5^{\circ} \mathrm{C}$. An IPCC Special Report on the impacts of global warming of $1.5^{\circ} \mathrm{C}$ above pre-industrial levels and related global greenhouse gas emission pathways, in the context of strengthening the global response to the threat of climate change, sustainable development, and efforts to eradicate poverty [Masson-Delmotte, V., P. Zhai, H.-O. Pörtner, D. Roberts, J. Skea, P.R. Shukla, A. Pirani, W. Moufouma-Okia, C. Péan, R. Pidcock, S. Connors, J.B.R. Matthews, Y. Chen, X. Zhou, M.I. Gomis, E. Lonnoy, T. Maycock, M. Tignor, and T. Waterfield (ed.)]. In Press. Available at: https://www.ipcc.ch/sr15/download/.

IPCC, 2019c: IPCC Special Report on the Ocean and Cryosphere in a Changing Climate [H.-O. Pörtner, D. C. R., V. Masson-Delmotte, P. Zhai, M. Tignor, E. Poloczanska, K. Mintenbeck, A. Alegría, M. Nicolai, A. Okem, J. Petzold, B. Rama, N.M. Weyer (ed.)]. In press. Available at: https://www.ipcc.ch/srocc/.

Jost, C. et al., 2015: Understanding gender dimensions of agriculture and climate change in smallholder farming communities. Climate and Development, 8(2), 133-144, doi:10.1080/17565529.2015.1050978.

Kamara, J. K., K. Agho and A. M. N. Renzaho, 2019: Understanding disaster resilience in communities affected by recurrent drought in Lesotho and Swaziland - A qualitative study. PLOS ONE, 14(3), e0212994, doi:10.1371/journal.pone.0212994.

Kanda, A., M. Murongazvombo and F. Ncube, 2017: Adapting household water use in rural Zimbabwe. International Journal of Environmental Studies, 74(3), 471-485, doi:10.1080/00207233.2017.1319622.

Kofod-Petersen, A., 2012: How to do a Structured Literature Review in computer science. 
Lesnikowski, A. et al., 2021: The Global Adaptation Mapping Initiative (GAMI): Part 3 - Coding protocol. Nature Protocol Exchange, doi:10.21203/rs.3.pex-1242/v1.

Makondo, C. C. and D. S. G. Thomas, 2018: Climate change adaptation: Linking indigenous knowledge with western science for effective adaptation. Environmental Science and Policy, 88, 83-91, doi:10.1016/j.envsci.2018.06.014.

Mashizha, T. M., 2019: Adapting to climate change: Reflections of peasant farmers in Mashonaland West Province of Zimbabwe. Jamba-J. Disaster Risk Stud., 11, 8, doi:10.4102/jamba.v11i1.571.

Mastrandrea, M. D. et al., 2011: The IPCC AR5 guidance note on consistent treatment of uncertainties: a common approach across the working groups. Climatic Change, 108(4), 675-691, doi:10.1007/s10584011-0178-6.

Mavhura, E., 2017a: Applying a systems-thinking approach to community resilience analysis using rural livelihoods: The case of Muzarabani district, Zimbabwe. International Journal of Disaster Risk Reduction, 25, 248-258, doi:https://doi.org/10.1016/j.ijdrr.2017.09.008.

Mavhura, E., 2017b: Building resilience to food insecurity in rural communities: Evidence from traditional institutions in Zimbabwe. Jamba-J. Disaster Risk Stud., 9(1), 9, doi:10.4102/jamba.v9i1.453.

Mugi-Ngenga, E. W. et al., 2016: Household's socio-economic factors influencing the level of adaptation to climate variability in the dry zones of Eastern Kenya. Journal of Rural Studies, 43, 49-60, doi:10.1016/j.jrurstud.2015.11.004.

Mupakati, T. and V. I. Tanyanyiwa, 2017: Cassava production as a climate change adaptation strategy in Chilonga Ward, Chiredzi District, Zimbabwe. Jàmbá: Journal of Disaster Risk Studies, 9(1), doi:10.4102/jamba.v9i1.348.

Mwaniki, F. and R. B. Stevenson, 2017: Farmers' uses of indigenous knowledge and practices to cope with climate change in Kilifi County, Kenya. International Journal of Climate Change: impacts and responses, 9(4), 53-65, doi:http://dx.doi.org/10.18848/1835-7156/CGP/v09i04/53-65.

Nakabugo, R., I. P. Mukwaya and S. Geoffrey, 2019: Adoption of Climate Smart Agricultural Technologies and Practices in Drylands in Uganda: Evidence from a Microlevel Study in Nakasongola District. Springer International Publishing, pp. 541-568.

Niang, I. et al., 2014: Africa. In: Climate Change 2014: Impacts, Adaptation, and Vulnerability. Part B: Regional Aspects. Contribution of Working Group II to the Fifth Assessment Report of the Intergovernmental Panel on Climate Change [Barros, V. R., C.B. Field, D.J. Dokken, M.D. Mastrandrea, K.J. Mach, T.E. Bilir, M. Chatterjee, K.L. Ebi, Y.O. Estrada, R.C. Genova, B. Girma, E.S. Kissel, A.N. Levy, S. MacCracken, P.R. Mastrandrea, and L.L. White (ed.)]. Cambridge University Press, Cambridge, United Kingdom and New York, NY, USA, 1199-1266 pp. 
Nkomwa, E. C. et al., 2014: Assessing indigenous knowledge systems and climate change adaptation strategies in agriculture: A case study of Chagaka Village, Chikhwawa, Southern Malawi. Physics and Chemistry of the Earth, 67-69, 164-172, doi:https://doi.org/10.1016/j.pce.2013.10.002.

Nyong, A., F. Adesina and B. O. Elasha, 2007: The value of indigenous knowledge in climate change mitigation and adaptation strategies in the African Sahel. Mitigation and Adaptation Strategies for Global Change, 12(5), 787-797, doi:10.1007/s11027-007-9099-0.

Ofoegbu, C., P. W. Chirwa, J. Francis and F. D. Babalola, 2016: Assessing forest-based rural communities' adaptive capacity and coping strategies for climate variability and change: The case of Vhembe district in south Africa. Environmental Development, 18, 36-51, doi:10.1016/j.envdev.2016.03.001.

Ologeh, I. O., J. B. Akarakiri and F. A. Adesina, 2018: Constraints and Limits to Climate Change Adaptation Efforts in Nigeria. Springer, pp. 159-174.

Opare, S., 2018: Adaptation to climate change impacts: coping strategies of an indigenous community in Ghana to declining water supply. Climate and Development, 10(1), 73-83, doi:10.1080/17565529.2016.1184610.

Otto, F. E. L. et al., 2018: Anthropogenic influence on the drivers of the Western Cape drought 2015-2017. Environmental Research Letters, 13(12), doi:10.1088/1748-9326/aae9f9.

Owen, G., 2020: What makes climate change adaptation effective? A systematic review of the literature. Global Environmental Change, 62, 102071, doi:10.1016/j.gloenvcha.2020.102071.

Oyerinde, G. T., E. A. Lawin and A. J. Odofin, 2017: Farmers' Responses to Changing Hydrological Trends in the Niger Basin Parts of Benin. Hydrology, 4(4), 52, doi:https://doi.org/10.3390/hydrology 4040052.

Petzold, J. et al., 2020: Indigenous knowledge on climate change adaptation: A global evidence map of academic literature. Environmental Research Letters, 15(11), 113007, doi:10.1088/1748-9326/abb330.

Recha, C. W., M. N. Mukopi and J. O. Otieno, 2014: Socio-Economic Determinants of Adoption of Rainwater Harvesting and Conservation Techniques in Semi-Arid Tharaka Sub-County, Kenya. Land Degradation and Development, 26(7), 765-773, doi:10.1002/Idr.2326.

Sadiq, M. A., J. K. M. Kuwornu, R. M. Al-Hassan and S. I. Alhassan, 2019: Assessing maize farmers' adaptation strategies to climate change and variability in Ghana. Agriculture (Switzerland), 9(5), doi:10.3390/agriculture9050090.

Sangeda, A. Z., D. D. Maleko and E. J. Mtengeti, 2013: Socio-economic and ecological dimensions of climate variability and change for agro-pastoral communities in central Tanzania. Livestock Research for Rural Development, 25(12). 
Sanogo, K. et al., 2016: Farmers' perceptions of climate change impacts on ecosystem services delivery of parklands in southern Mali. Agroforestry Systems, 91(2), 345-361, doi:10.1007/s10457-016-9933-z.

Shemsanga, C. et al., 2018: Indigenous knowledge on development and management of shallow dug wells of Dodoma Municipality in Tanzania. Applied Water Science, 8(2), doi:10.1007/s13201-018-0697-7.

Singh, C., 2018: Is participatory watershed development building local adaptive capacity? Findings from a case study in Rajasthan, India. Environmental Development, 25, 43-58, doi:10.1016/j.envdev.2017.11.004.

Spear, D. and A. Chappel, 2018: Livelihoods on the edge without a safety net: The case of smallholder crop farming in north-central Namibia. Land, 7(3), doi:10.3390/land7030079.

Tambo, J. A. and T. Wünscher, 2017: Enhancing resilience to climate shocks through farmer innovation: evidence from northern Ghana. Regional Environmental Change, 17(5), 1505-1514, doi:10.1007/s10113017-1113-9.

Thorn, J., T. F. Thornton and A. Helfgott, 2015: Autonomous adaptation to global environmental change in peri-urban settlements: Evidence of a growing culture of innovation and revitalisation in Mathare Valley Slums, Nairobi. Global Environmental Change, 31, 121-131, doi:10.1016/j.gloenvcha.2014.12.009.

UN Water, 2013: Climate change adaptation is mainly about water, 2 pp.

United Nations Economic Commission for Europe, 2009: Guidance on water and adaptation to climate change. United Nations Economic Commission for Europe (UNECE), 1-144 pp. Available at: https://unece.org/info/publications/pub/21691.

United Nations Environment Programme, 2021: Adaptation Gap Report 2020. Nairobi, 120 pp. Available at: https://www.unep.org/resources/adaptation-gap-report-2020.

Vaismoradi, M., J. Jones, H. Turunen and S. Snelgrove, 2016: Theme development in qualitative content analysis and thematic analysis. Journal of Nursing Education and Practice, 6(5), doi:10.5430/jnep.v6n5p100.

Vaismoradi, M., H. Turunen and T. Bondas, 2013: Content analysis and thematic analysis: Implications for conducting a qualitative descriptive study. Nursing \& Health Sciences, 15(3), 398-405, doi:10.1111/nhs.12048.

Williams, P. A., O. Crespo and M. Abu, 2019: Adapting to changing climate through improving adaptive capacity at the local level - The case of smallholder horticultural producers in Ghana. Climate Risk Management, 23, 124-135, doi:10.1016/j.crm.2018.12.004.

Williams, P. A., L. Sikutshwa and S. Shackleton, 2020: Acknowledging Indigenous and Local Knowledge to Facilitate Collaboration in Landscape Approaches - Lessons from a Systematic Review. Land, 9(9), 331, doi:10.3390/land9090331. 
Williams, P. A. et al., 2021: Feasibility assessment of climate change adaptation options across Africa: An evidence-based review. Environmental Research Letters, 16, 073004, doi:10.1088/1748-9326/ac092d.

Yohannes, Z., M. Teshome and M. Belay, 2019: Adaptive capacity of mountain community to climate change: case study in the Semien Mountains of Ethiopia. Environment, Development and Sustainability, 22(4), 3051-3077, doi:10.1007/s10668-019-00334-3.

\section{Figures}




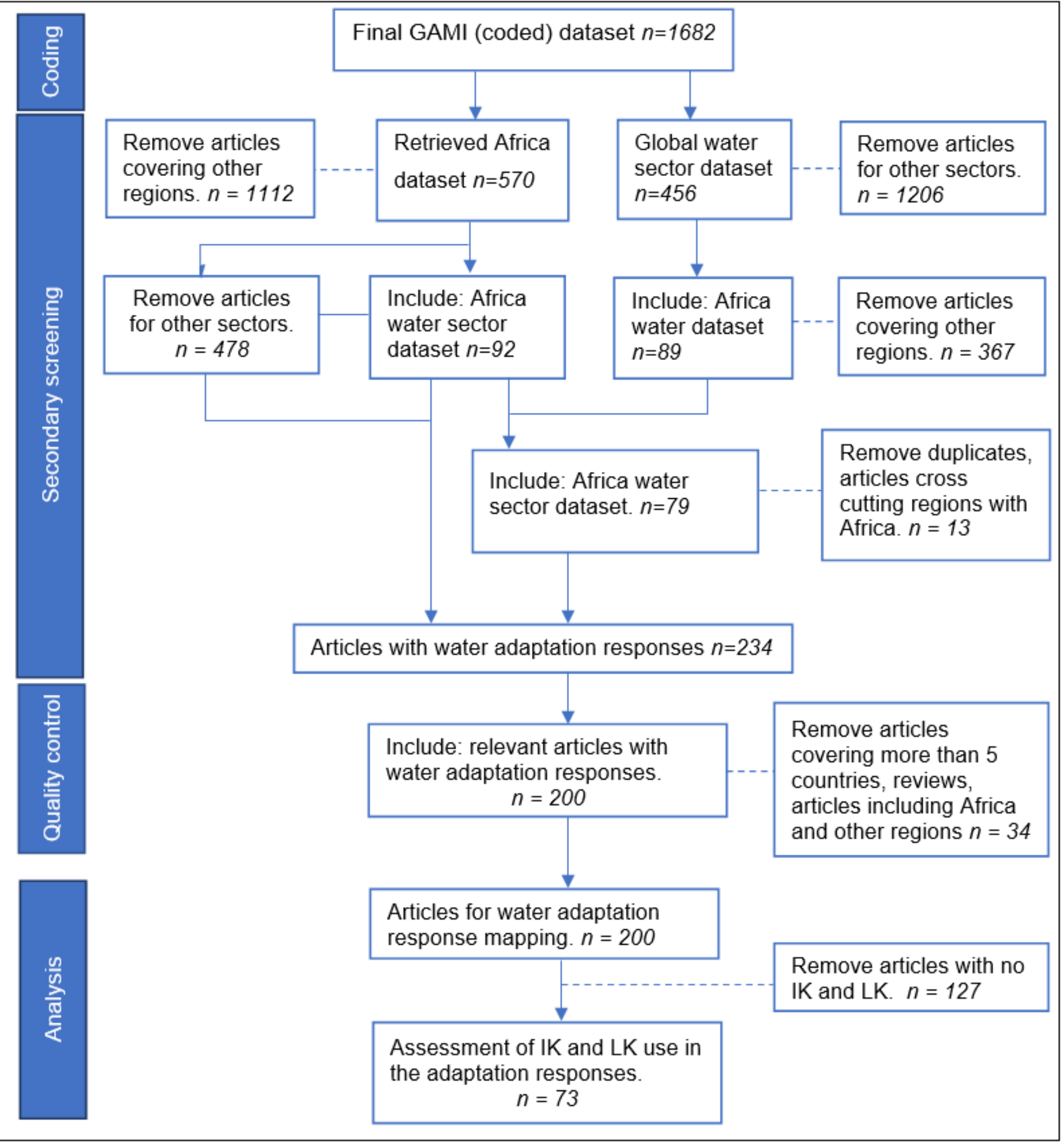

\section{Figure 1}

Flowchart of the procedure used in this study. Adapted from Haddaway et al. (2018) ROSES (RepOrting standards for Systematic Evidence Syntheses) for conducting environmental systematic reviews and systematic maps procedure. 
a. Number of studies with WAR

- 1-4

- 5-9

- 10-14

15-19

20-30

Number of studies with IK \& LK

- 1-4

- 5-9

10-14

$15-19$

$20-30$

Countries with WAR data

Countries with no data on WAR

b. Number of climate hazards associated with water adaptation responses (WAR)

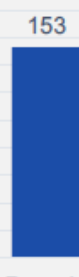

Drought

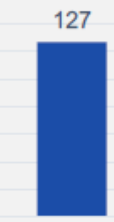
Precipitation
variability

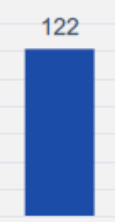

General climate impacts

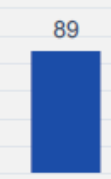

Extreme precipitation frequency and inland and intensity flooding of extreme
heat

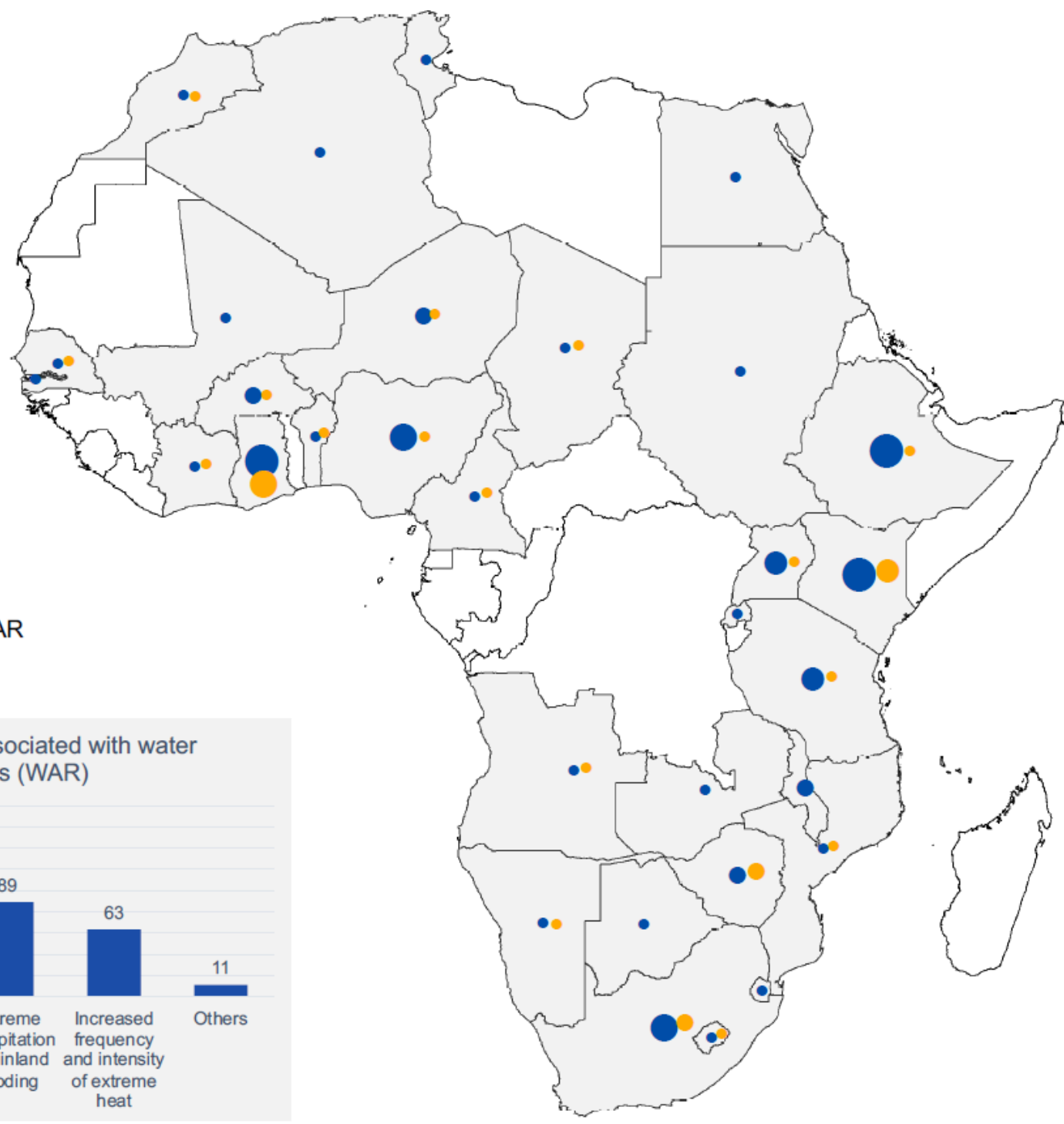

\section{Figure 2}

a). Geographic distribution of evidence of water adaptation responses (WAR) (blue dots) and the water adaptation responses influenced by IK and LK (orange dots) in Africa between 2013 and 2019, b). Climate hazards that are responded to in the articles.

\section{Supplementary Files}

This is a list of supplementary files associated with this preprint. Click to download.

- SupplementaryMaterial3.xlsx

- SupplementaryMaterial.docx

- Table5.docx 